\title{
A GESTÃO DO CONHECIMENTO E A INOVAÇÃO: UM ESTUDO DE CASO EM UM RESTAURANTE DA CIDADE DE NATAL/RN
}

\author{
C. R. L. B. SOUZA', M. F. D'ANJOUR ${ }^{2}$, B. C. MEDEIROS ${ }^{2 *}$ e M. E. M. AÑEZ ${ }^{3}$ \\ ${ }^{1} \mathrm{SEBRAE}$ \\ ${ }^{2}$ Instituto Federal de Educação, Ciência e Tecnologia do Rio Grande do Norte \\ ${ }^{3}$ Universidade Federal do Rio Grande do Norte \\ bruno.campelo@ifrn.edu.br*
}

Artigo submetido em setembro/2015 e aceito em outubro/2015

DOI: 10.15628/empiricabr.2015.3443

\section{RESUMO}

O presente estudo tem como objetivo geral identificar os elos de relação da gestão do conhecimento para a inovação em um restaurante de pequeno porte na cidade de Natal/RN. O estudo caracteriza-se como do tipo descritivo conduzido por meio de um estudo de caso único de natureza qualitativa. Os dados foram coletados por meio de uma entrevista semiestruturada em profundidade, desenvolvida com base no modelo de Oliveira et al (2013), e tratados através da técnica se análise de conteúdo. Os resultados apontam que a criação, o desenvolvimento e o compartilhamento de conhecimentos entre os colaboradores são incentivados informalmente, o que tem proporcionado resultados no quesito inovação, e um diferencial em relação aos demais restaurantes do segmento. No entanto, a organização tem desenvolvido seu processo de inovação sem uma sistematização dos conhecimentos adquiridos, os quais não são armazenados, demonstrando assim que não há uma cultura na empresa voltada para a gestão do conhecimento. Por fim, é importante que a organização atente para a necessidade de gerar vantagem competitiva por meio do uso de mecanismos formais de gerenciamento do conhecimento, e assim, ser capaz de transformar o seu capital intelectual em ativo intangível.

PALAVRAS-CHAVE: Gestão do conhecimento. Inovação. Estudo de caso.

\section{KNOWLEDGE MANAGEMENT AND INNOVATION: A CASE STUDY IN A RESTAURANT IN THE CITY OF NATAL/RN}

\begin{abstract}
The present study aims to identify the links of general relationship of knowledge management for innovation in a small restaurant in the city of Natal/RN. The study is characterized as descriptive type driven by a single case study of qualitative nature. The data were collected by means of a semi-structured in-depth interview, developed based on the model of Oliveira et al. (2013), and treated through content analysis. The results show that the creation, the development and sharing of knowledge between employees are encouraged informally, which has provided results in terms of
\end{abstract}

innovation, and a differential compared to other restaurants of the segment. However, the Organization has developed its innovation process without a systematization of the knowledge acquired, which are not stored, thus demonstrating that there is a culture in the company focused on knowledge management. Finally, it is important that the organization pay attention to the need to generate competitive advantage through the use of formal knowledge management mechanisms, and thus be able to turn your intellectual capital in intangible assets.

KEYWORDS: Knowledge management. Innovation. Case study. 


\section{INTRODUÇÃO}

Este artigo é resultado do Programa do SEBRAE Nacional, denominado Agentes Locais de Inovação (ALI) desenvolvido em parceria com o CNPq - Conselho Nacional de Desenvolvimento Científico e Tecnológico, cujo objetivo é trazer oportunidades e novas soluções para as Micro e Pequenas Empresas de todo o Brasil inovarem, buscando-se assim um diferencial competitivo e a implantação da cultura da inovação nessas empresas, e também, fomentar a pesquisa sobre a inovação (SEBRAE, 2014).

Neste contexto o termo inovação não é algo contemporâneo, já remonta aos anos 60 quando Schumpeter (1961) escreveu a teoria do desenvolvimento econômico na qual destaca "[...] o empresário inovador - agente econômico que traz novos produtos para o mercado por meio de combinações mais eficientes dos fatores de produção, ou pela aplicação prática de alguma invenção ou inovação tecnológica".

Para a inovação, a informação e o conhecimento representam ferramentas que podem e devem ser transformadas em mecanismo de ruptura de um padrão usual ou de criação de uma vantagem competitiva frente ao concorrente. Para a administração, tal ferramenta é mais perceptível no pensamento sistêmico cujo conceito foi definido por Morgan (2009) no qual as empresas são organismos vivos que interagem com o meio em que vivem e de onde sofrem influências dele, cujo conceito é que o todo é maior do que a soma de suas partes.

As empresas são organismos abertos que sofrem e provocam mudanças no ambiente no qual estão inseridas. Senge (1990) retrata que a quinta disciplina é denominada de raciocínio sistêmico, como uma mudança de mentalidade, pois "a realidade é feita de círculos, mas nós só vemos linhas retas, e é aí que começam nossas limitações ao raciocínio sistêmico". Para expandilo a busca por informações internas e externas se faz importante ampliando o que ele denomina de modelo mental.

No cenário de mudanças é dito que "a inovação é um processo dinâmico em que o conhecimento é acumulado por meio do aprendizado e da interação", que tanto pode ser tácito como adquirido por meio de interações entre diversos atores que compõem esse cenário, seja pela transferência e difusão de ideias, experiências adquiridas pelas habilidades humanas no conceito de "learning by doing" - aprender fazendo - ou pela contratação de consultorias, know how, e tantas outras formas. Para inovar é preciso utilizar conhecimento novo ou novo modelo de utilização para o já existente, de fontes internas - inovação fechada - ou de ambas (internas e externas) - inovação aberta.

Segundo o "Guia para Inovação" do SEBRAE/PR (2010) das empresas que incluíram a inovação em suas práticas $62 \%$ apresentaram aumento da produção, $46 \%$ no faturamento e $39 \%$ maior produtividade dos colaboradores. De acordo com pesquisa realizada pela empresa Innoscience (2014) em parceria com o IEL/RS, aplicada em novembro de 2011, as principais fontes de informação para a inovação estão com os funcionários (60\%); Clientes/Consumidores (54\%); Universidades (32\%) e Fornecedores (19\%).

Isso vem reforçar o conceito de Inovação aberta que segundo a Universidade Corporativa do SEBRAE (2014) reflete a busca de informações em todos os ambientes para que a inovação seja mais efetiva, nesse contexto vale a pena buscar conhecimento até com os concorrentes 
(benchmarking). Nesse artigo estuda-se o conhecimento para alavancagem da inovação no segmento de restaurantes.

Segundo o Anuário Brasileiro da Alimentação Fora do Lar disponível no portal ISSUU (2014) estima-se um gasto maior com alimentação fora do lar passando de 31\% para 37\% em 2014 e para 2020 uma perspectiva de 45\%. Antes eram servidas 57 milhões de refeições e com essa projeção sobe para mais de 80 milhões. A tendência é de que as famílias além de manterem o almoço e jantar como maior fonte de faturamento dos restaurantes incluirão café da manhã ou o lanche da tarde. Esse segmento cresce em média $15 \%$ e o fator mais predominante é o acesso das mulheres ao mercado de trabalho, modificando a estrutura que precisa de serviços mais rápidos e o aumento da renda da família, aliando a falta de tempo à necessidade de tornar mais práticos esses processos.

O ISSUU (2014) apresenta que a maior preocupação dos brasileiros é voltada para a segurança alimentar e que os restaurantes precisam aliar qualidade no atendimento, preços acessíveis e, principalmente, qualidade no produto. No Brasil existem 336.492 restaurantes comerciais, desses 2.510 encontra-se no Rio Grande do Norte o que corresponde a 0,75\% do total geral. Para o consumidor a ida ao restaurante está mais ligada a "satisfação pessoal" do que ao consumo de produtos, para tanto reservam $1 / 4$ do orçamento familiar o que correspondeu a um gasto de 31,1\% em 2012.

De acordo com o IBGE (2014) o segmento de serviços prestados às famílias registrou no Brasil uma variação de 11,2\% em junho de 2014 em relação ao mês de junho de 2013, já o RN registrou uma variação de 7,6\% em junho de 2014 em relação ao mesmo mês do ano anterior. 0 que se mostra inferior ao crescimento do Brasil.

Neste contexto, destaca-se como campo de pesquisa as Micro e Pequenas Empresas que atuam no segmento de alimentos na cidade de Natal/RN. Assim, o presente estudo apresenta como questão central de pesquisa identificar: como se dá o impacto da gestão do conhecimento para a inovação em um restaurante de pequeno porte na cidade de Natal/RN? Quanto ao objetivo geral foi o de identificar os elos de relação da gestão do conhecimento para a inovação em um restaurante de pequeno porte na cidade de Natal/RN, a partir do modelo de Oliveira et al (2013).

O artigo encontra-se estruturado da seguinte forma: primeira parte que está inclusa a introdução, apresentou-se a contextualização e o objetivo da pesquisa; na segunda análise do gerenciamento dos recursos do conhecimento e sua relação com a inovação; já na terceira, consta a metodologia utilizada para alcançar o objetivo; quarta parte, análise e discussão dos resultados; quinta e última parte, considerações finais, as limitações da pesquisa e a possibilidade de trabalhos futuros.

\section{TEORIA DO CONHECIMENTO}

A Teoria do Conhecimento surge como parte integrante dos estudos filosóficos e somente na Idade Moderna aparece como disciplina independente dentro da filosofia, segundo Hessen (2000) é atribuído ao Inglês John Locke a autoria dessa independência pela obra publicada em 1690 que trata as questões do conhecimento, desde sua origem, a essência e a certeza do conhecimento humano. No mesmo livro, Hessen destaca que para a filosofia continental a autoria é dada a Immanuel Kant com sua obra “A crítica da razão pura" publicada em 1781. 
Dentro desse horizonte, de conhecimento como base para a inovação, segundo Bachmann e Destefani (2008) a ambiência inovadora trata exatamente das fontes internas e externas de conhecimento e é preciso aprender a gerenciar tudo isso e há nas teorias algumas divergências de conceito sobre o que é dado, o que é informação e o que vem a ser conhecimento. Uns acreditam que dado é a menor unidade da informação e que a informação precisa ser processada para virar conhecimento. Davenport (1998) relata que "conhecimento não é dado nem informação, embora esteja relacionado com ambos e as diferenças entre esses termos sejam normalmente uma questão de grau".

A partir do conceito de Davenport (1998) criou-se um modelo, Figura 1, para representar o que vem a ser essa diferenciação e essa associação entre dados, informação, conhecimento e a relação com os meios de comunicação utilizados, quais os procedimentos que diferenciam os graus. $E$, também, que o excesso de conhecimento não catalogado adequadamente pode vir a transformá-lo em dado novamente, caso não haja uma boa gestão.

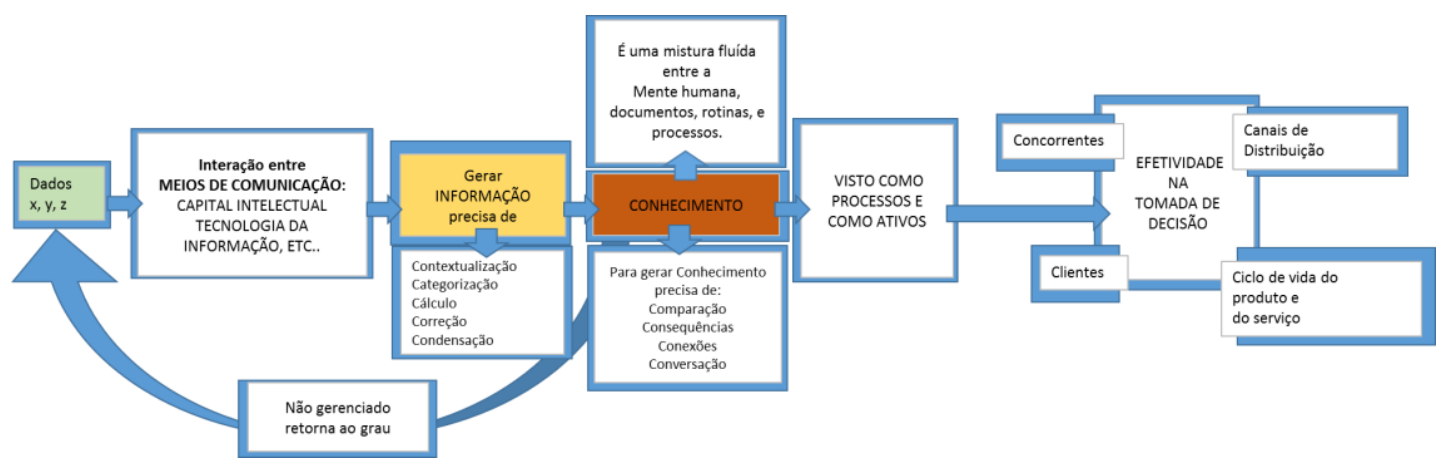

Figura 1: Diferenciação entre dados, informação e conhecimento e os atores e processos envolvidos nesse caminho de construção do conhecimento e retroação

Fonte: Adaptado de Davenport (1998)

Davenport (1998) ainda coloca que conhecimento é uma vantagem sustentável que deve ser mantida em poder da empresa, o que sabe - como utiliza o que sabe - e com que rapidez faz isso, ou seja, as empresas precisam saber o que sabem.

\section{GESTÃO DO CONHECIMENTO E INOVAÇÃO}

A Gestão do Conhecimento passa por um momento em que a globalização dissemina de forma contínua as informações, e portanto, institui-se o desafio de gerir aquilo que realmente é interessante para o negócio no campo empresarial. Gerenciar o conhecimento é uma tarefa um tanto complexa, mas necessária. Lastres $(1999$, p. 28$)$ relata que "a informação e conhecimento sempre constituíram importantes pilares dos diferentes modos de produção". Neste contexto, é inegável a importância do conhecimento e, principalmente, da sua gestão como fonte criativa para a inovação.

Para Johannessen, Olsen e Olaisen (1999, p. 124) a visão organizacional direciona a criação de conhecimento, permite a integração e aplicação deste para reforçar o processo de inovação nas empresas. E, ainda, o conhecimento inicia e suporta a inovação organizacional, conforme apresentado na Figura 2. A relação existente entre o processo de inovação, a visão organizacional é sustentado pela criação, integração e aplicação do conhecimento, isso permite as empresas 
criarem uma constante entre a busca de conhecimento e a manutenção das inovações em seus ambientes.

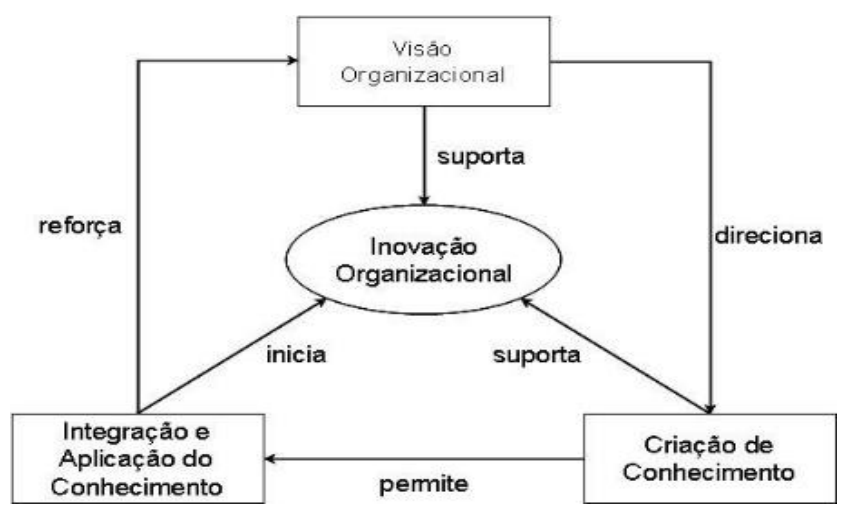

Figura 2: Visão, conhecimento e inovação organizacionais

Fonte: Johannessen, Olsen e Olaisen (1999, p.124)

Para Barroso e Gomes (2013) gerir o conhecimento é identificar e mapear o capital intelectual, e dessa forma, gerar novos conhecimentos e vantagens competitivas, proporcionar acesso às informações da empresa onde deverá ser compartilhado o que há de melhor como parte integrante das corporações. Transformar conhecimento em ativo intangível. Esse ativo é composto por estruturas externas (clientes - fornecedores - imagem da empresa), estruturas internas (patentes, conceitos, modelos, programas de computadores e sistemas de administração) e a competência dos funcionários, definido também como individual, capital humano e, posteriormente, capital intelectual (capacidade de ação diante da prática diária).

Barroso e Gomes (2013) afirmam que não só de ativos tangíveis, são formadas as empresas. Assim, gerir conhecimento é a arte de gerar valor e transformá-lo em ativo intangível, tendo a capacidade de enxergar esse patrimônio como conhecimento e fluxos de conhecimentos. E que a gestão do conhecimento é a gerência holística da informação, sem a qual não se produz conhecimento.

Dentro do contexto do conhecimento a OCDE (2006), apresenta a inovação como a formação de algo novo ou extremamente melhorado, podendo ocorrer em produtos, processos, marketing e organizacional e que seja aceito pelo mercado, gerando vantagem competitiva refletida em aumento de receitas ou redução de custos. Classifica como inovação em produtos e/ou serviços um novo item do cardápio, um serviço complementar, dentre outros; em processos, aquisição de novos equipamentos, novas formas de manipulação de produtos, etc.; no marketing novos canais de venda, novas formas de divulgação, são alguns exemplos e, organizacional, que engloba a parte de gestão da empresa e dentro dessa dimensão encontramos o grau de importância da gestão do conhecimento classificada como Ambiência Inovadora, que trata da capacitação contínua de gestores e colaboradores, participação em eventos ligados ao segmento como fontes de inspiração e informação, meios formais de estímulos à inovação.

A teoria da inovação foi fortemente influenciada pelo trabalho de Schumpeter (1961). Ele prega, também, o conceito de "destruição criadora" em que inovação é um processo constante de substituição do velho pelo novo. Ele ainda trata dos conceitos de inovações radicais que provocam rupturas mais intensas e inovações incrementais que continuam o processo de mudança. Para 
tanto o conhecimento, a criatividade e a abertura ao risco (calculado) são as bases para esse processo de evolução.

No Figura 3 a Visão Baseada em Recursos - RBV enxerga o gerenciamento dos recursos e competências como a fonte para a criação de vantagem competitiva e coloca a história das empresas como uma "Dependência de Trajetória", ou seja, o passado é fortemente influenciador das inovações e tem como foco o estilo incremental. Já na "Criação de Trajetória" esse passado embora importante, não pode engessar o processo de inovação e o foco é mais para as de ruptura (BITTENCOURT, 2014). Para a visão baseada no conhecimento há uma necessidade de formar diversas redes que são essenciais para as organizações.

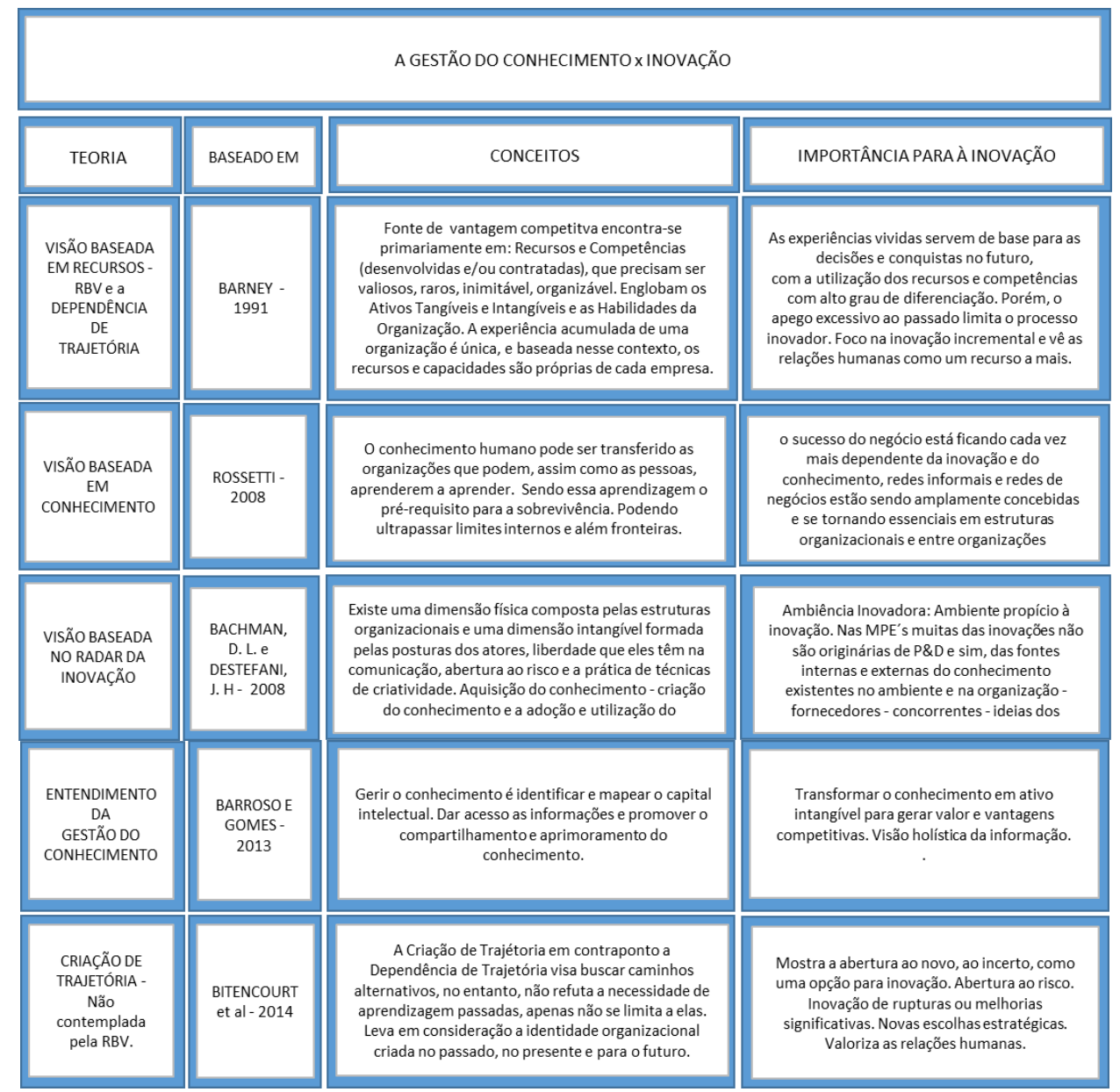

Figura 3: Relação entre teorias do conhecimento e a inovação

Segundo Rossetti (2008) a memória organizacional da empresa é formada pelo mapeamento das competências internas, onde é necessário identificar onde estão da seguinte forma: Quem faz o quê? Quem sabe o quê? Quem é bom em quê? E no ambiente externo pelas organizações, clientes, fornecedores e concorrentes. Empresa com cultura organizacional voltada para o conhecimento é capaz de criar ou manter grupos, qualidade, confiabilidade, flexibilidade e capacidade de resposta, orientado para um serviço que atenda não só as necessidades dos clientes como possa, inclusive, surpreendê-los já que restaurantes são classificados como serviços de turismo e mais do que vender um prato de comida, está voltado para promover sensações agradáveis em sua clientela. 


\section{METODOLOGIA}

A presente pesquisa se propôs a analisar o impacto da gestão do conhecimento para a inovação nas EPP's brasileiras do segmento de restaurantes em Natal/RN, inscritas no Programa ALI/SEBRAE. Assim, quanto aos seus objetivos a pesquisa classifica-se como um estudo do tipo descritivo, que segundo Gil (2002) busca fazer a "descrição das características de determinada população ou fenômeno ou, então, o estabelecimento de relações entre variáveis", neste caso a relação da variável do grau geral de inovação e do grau geral da ambiência do segmento de restaurantes comparados aos graus específicos do Restaurante Con Xin China, objeto do estudo.

Quanto aos procedimentos adotou-se o modelo de estudo de caso, pois segundo Yin (2005) "é o delineamento mais adequado para a investigação de um fenômeno contemporâneo dentro de seu contexto real", servindo para explorar situações reais sem limites definidos; manter o fator unitário do objeto estudado; montar o cenário da investigação em pauta e, também, contribuir com hipóteses ou criar teorias a respeito do assunto abordado. Nesse caso é apropriado, pois o estudo aborda questões contextuais pertinentes ao que está sendo analisado.

Quanto à natureza o estudo é predominantemente qualitativo, que segundo Flick (2009) leva em consideração a contextualização e o fenômeno para se entender uma determinada questão. Muitos se baseiam em um estudo de caso que é de importância fundamental para o entendimento do que é estudado.

A técnica de coleta de dados se deu por meio de uma entrevista semiestruturada que de acordo com Gil (1999) entrevista é uma técnica utilizada para o entrevistador fazer perguntas e obter respostas do entrevistado de forma presencial. E é semiestruturada, por sua vez, pois segue um roteiro já estruturado, mas a realização dela flui de maneira similar a uma conversa casual (DINIZ, 2006). Essa entrevista foi realizada em 18 de setembro de 2014 e durou aproximadamente duas horas, com o proprietário, em seu estabelecimento. Uma segunda técnica de coleta de dados utilizada foi o Radar da Inovação, usado no presente estudo para identificar o grau de inovação da empresa estudado e possibilitar a comparação com o grau de inovação de outras empresas do mesmo segmento na cidade de Natal/RN.

Quanto à amostragem, foi definida uma técnica qualitativa denominada de amostragem crítica que segundo Flick (2009) "visa àqueles casos nos quais as relações a serem estudadas tornam-se especialmente claras ou que são particularmente importantes [...] para o funcionamento de um programa a ser avaliado". Atendendo questões éticas esse procedimento foi firmado mediante termo formal de consentimento livre e esclarecido do empresário para divulgação dos dados coletados e do nome de sua empresa.

Como delimitação da análise escolheu-se a dimensão Ambiência Inovadora do Radar, dentre as treze existentes, por que trata, entre outras coisas, das diversas formas de obter conhecimento em Fontes Externas (Instituições de Ensino, Concorrência, Seminários, Consultorias, Know-How, Royalties, etc) e, como Fonte Interna de conhecimento a Coleta de Ideias (dos colaboradores) e um grupo de 37 empresas do segmento de restaurantes da cidade de Natal, e também, o estudo de caso de uma delas, cujo grau de inovação mostrou-se um dos mais expressivos dentre aquelas com grau de inovação já detectado, buscando fazer uma triangulação entre a entrevista do gestor, o radar e a teoria acerca da gestão do conhecimento e o impacto para a inovação. 
Os tópicos que compuseram o roteiro de entrevista seguiram o modelo de Oliveira et al. (2013), com questões que buscam identificar elementos da gestão do conhecimento sendo está dividida nas seguintes categorias: a criação, o desenvolvimento, o armazenamento, o compartilhamento e o grau de importância do conhecimento como item fundamental da inovação em produtos e processos no restaurante de propriedade do entrevistado. Essa entrevista foi formatada na Figura 3-memos da entrevista ou codificação, parte integrante dessa pesquisa que será analisada mais adiante.

Para a análise da entrevista semiestruturada utilizou-se a análise de conteúdo de Bardin (1979) que consiste em uma técnica de análise da entrevista e da comunicação que objetiva a descrição de conteúdo que permitam fazer inferências a respeito das mensagens levando-se em consideração a forma como foram produzidas pelo entrevistado e recebidas pelo entrevistador e, para a análise qualitativa, o que serve de fonte são as frequências com que surgem certas características das informações produzidas pelo entrevistado. E, também, foi utilizado o Radar da Inovação, modelo de Bachmann e Destefani (2008) para contextualizar a análise dos resultados. Esse cálculo é elaborado por meio da estatística descritiva com o cálculo da média detectado no segmento estudado, mas os dados foram analisados qualitativamente mediante entrevista e pesquisa de campo. De acordo com Lakatos $(2003,185 p)$ a pesquisa de campo tem como enfoque a busca por "[...] conhecimentos acerca de um problema, para o qual se procura uma resposta, ou de uma hipótese, que se queira comprovar, ou, ainda, descobrir novos fenômenos ou as relações entre eles".

A classificação do Radar da Inovação de acordo com Bachmann e Destefani (2008) é feita da seguinte forma: Grau de inovação de 1,0 a 2,5 - para empresas pouco inovadoras, que não tem práticas de inovações em seu contexto, seguem no mercado sem observar tendências, sem modificar seus processos, etc., de 2,6 a 3,5 - inovadoras ocasionais, fazem esporadicamente algumas inovações, mas não há uma sistemática e formalização desses processos e de 3,6 a 5,0 quando a inovação está presente, ou seja, nível de excelência quanto à prática da inovação, que são as empresas que estão sempre voltadas a melhorias contínuas, a criação de diferenciais e vantagens competitivas, conforme a Tabela 1 em seguida:

Tabela 1: Classificação das empresas quanto ao grau mensurado

\begin{tabular}{c|c}
\hline GRAU DE INOVAÇÃO & CLASSIFICAÇÃO \\
\hline $1,0-2,5$ & Pouco inovadoras \\
\hline $2,6-3,5$ & Inovadoras ocasionais \\
\hline $3,6-5,0$ & Inovadoras sistêmicas \\
\hline
\end{tabular}

Fonte: Adaptado de Bachmann e Destefani (2008)

Para o cálculo dos escores do radar foi encontrada a média de 34 empresas do segmento de restaurantes incluindo o pesquisado nesse artigo. Essa média do radar geral e da ambiência inovadora foi comparada com a média específica do restaurante Con Xin China o que será analisado mais detalhadamente logo abaixo.

\section{ANÁLISE E DISCUSSÃO DOS RESULTADOS}

O Restaurante Con Xin China foi fundado em 1995 em Natal/RN e, surgiu da necessidade do patriarca manter seu padrão de vida e da família após sua aposentadoria da Volvo, empresa onde trabalhou por vários anos. Primeiramente, a ideia foi trazer uma franquia do China in Box, 
porém naquela época não era do interesse do proprietário daquela empresa aderir a esse modelo de negócio. Daí surgiu o primeiro delivery, entrega em domicílio, de comida chinesa na grande Natal. Em 1997 a empresa mudou-se do bairro de Ponta Negra para o de Capim Macio, no qual encontra-se atualmente, já iniciando com o self service, massas, bar e petiscos.

O sócio que respondeu a essa pesquisa é natural de Bauru/SP, graduado em Engenharia da Computação. Possui formação, também, de Cozinheiro Profissional. Embora o nome remeta à culinária chinesa, o motivo dessa escolha se deve ao fato que a proposta era a de entregar em qualquer canto da cidade, "até nos confins da China". Ao diversificar o serviço e produtos ampliou seu mix e passou a ofertar tanto a cozinha nacional, como a internacional e manteve a já existente.

A empresa analisada tem formalmente definida a missão e a visão e hoje conta com mais de cinquenta colaboradores, entre próprios, familiares e terceirizados, iniciou com seis funcionários, sendo dois familiares, e está hoje enquadrada como Empresa de Pequeno Porte optante do Simples - Sistema tributário simplificado para micro e pequenas empresas.

Para a escolha do Con Xin China, marca já registrada no INPI - Instituto Nacional de Propriedade Intelectual, e do seu respectivo proprietário, foi levado em consideração os quesitos conveniência que segundo Flick (2009) é a "seleção daqueles casos mais acessíveis sob determinadas condições" e o grau de importância das informações para esse estudo, mediante desempenho alcançado no radar conforme figura 5 abaixo. Para tanto, considerou-se, também, a facilidade com que o entrevistado proporcionou, ao acesso da pesquisadora às informações necessárias e a importância do pioneirismo desse empreendimento para o setor de delivery, já citado anteriormente, e self service da capital natalense e suas particularidades, que incluem o nível de inovação e de ambiência inovadora detectado, um dos mais elevados dentre as empresas do mesmo segmento.

\section{RADAR DA INOVAÇÃO}

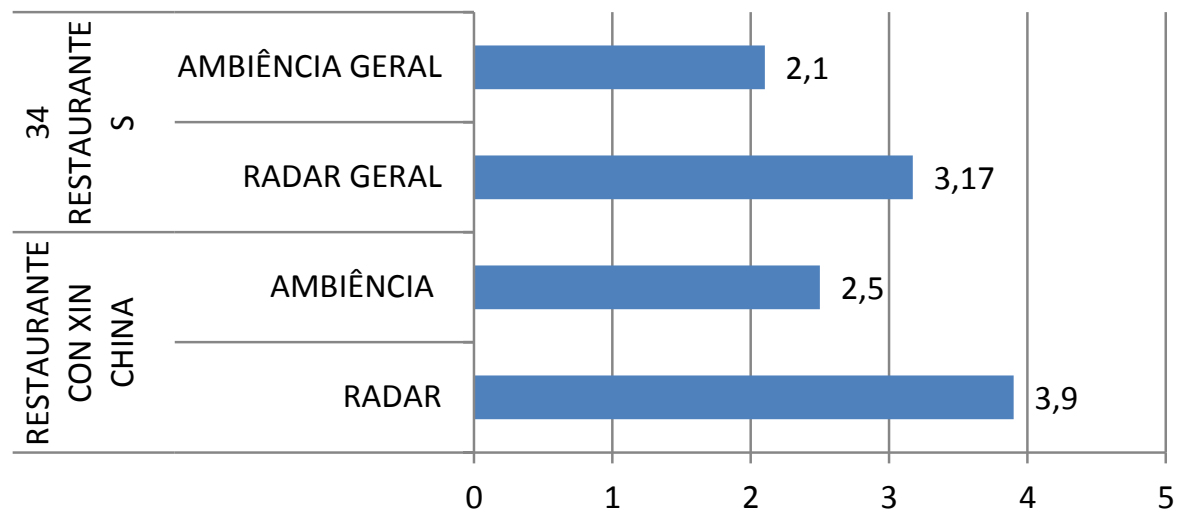

Figura 4: Análise do radar da inovação: Média do Segmento com amostra de 34 restaurantes x restaurante Con Xin China

Fonte: Dados da Pesquisa (2014)

Como demonstrado no Figura 4, a média geral do radar de inovação das demais empresas do mesmo segmento do restaurante Con Xin é de 3,17, o que representa empresas inovadoras ocasionais, sendo a média do grau geral de inovação da empresas estuda de 3,9, ficando 0,73 acima da média do segmento, mostrando que o restaurante em questão está no patamar de inovadoras sistemáticas, enquanto a média geral do setor aponta empresas inovadoras ocasionais. No quesito 
que analisa as fontes de conhecimento, Ambiência Inovadora, a média geral do segmento é de 2,10 e da empresa estudada é de 2,5, diferencial de 0,4 do geral. Ou seja, embora a empresa esteja inserida em um contexto de restaurantes com inovações ocasionais, ele se destaca individualmente como inovador sistêmico.

Corroborando a essa análise dos escores, identificou-se com a entrevista que a empresas está desenvolvendo uma inovação em produtos com informações colhidas junto aos fornecedores, que conforme Barroso e Gomes (2013) são estruturas externas que fornecem conhecimento. Como exemplo cita-se aqui a nova fritadeira adquirida pela empresa que proporcionou redução no consumo de gás, de óleo, diminuição da temperatura interna da cozinha e padronização na fritura, pois a temperatura é autorregulada, proporcionando independência de mão de obra especializada, ou seja, redução de resíduos ambientais, melhorias no conforto para os colaboradores proporcionando-Ihes bem estar, redução de custo e ganho de qualidade. Aliando inovação com responsabilidade social e adequação as normas legais.

A codificação da entrevista que foi baseada no método de Oliveira et al (2013) representada Figura 5, sendo estruturada da seguinte forma: transformação do conhecimento em ativo intangível à serviço da inovação baseado também em Barroso e Gomes (2013) e o Radar da Inovação (BACHMANN; DESTEFANI, 2008). Esse conhecimento é buscado em fontes internas e externas. No restaurante em questão observa-se que o conhecimento voltado para a inovação não tem nenhum tratamento formal. Ela é pensada basicamente para atender as necessidades dos clientes e que há resistência da maioria dos envolvidos no processo às mudanças e inovações. $O$ processo parte, quase que exclusivamente, do entrevistado e de forma intuitiva, quando em suas conversas de grupo e em viagens que faz aliando lazer e benchmarking.
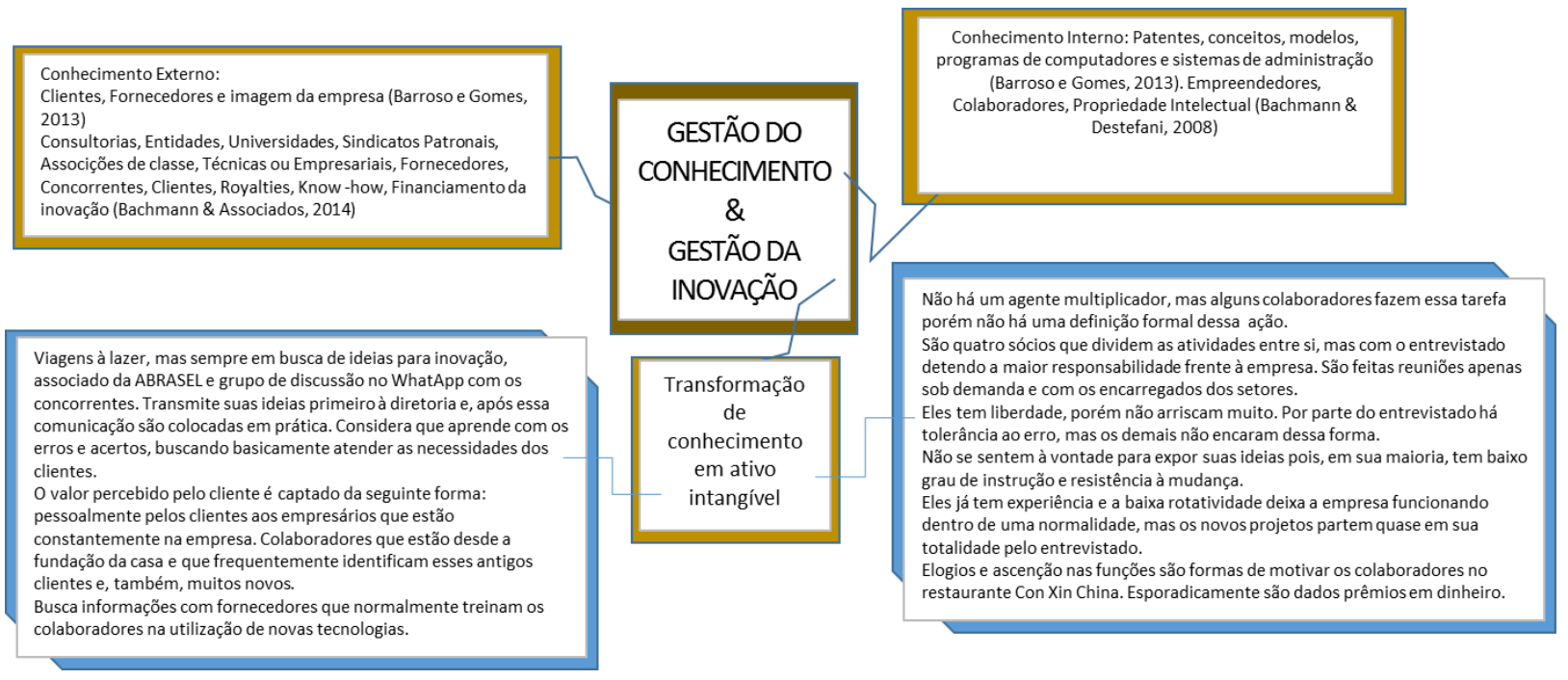

Figura 5: Codificação da entrevista, segundo Bardin (1979)

Fonte: Dados da Pesquisa (2014)

Não existe na empresa estudada um processo formam de registro do conhecimento e do processo de inovação, apenas existe a decisão de inovar e estas inovações geradas são incorporadas as práticas, com reuniões sob demanda com os colaboradores da área específica. Não há muito apoio e/ou participação dos demais sócios e gestores. Existem duas realidades: uma de abertura ao diálogo para apresentação de ideias e tolerância ao erro necessário à 
experimentação e outra, antagônica que não encara da mesma forma. Cenário corriqueiro de empresas com gestão familiar.

E, em relação ao grau de importância do conhecimento para a inovação de produtos e processos não há agente multiplicador específico, apenas os mais antigos treinam os mais novos ou, quando se trata de inovação em processos, o próprio fabricante ou alguém contratado especialmente para essa função faz a disseminação desse conhecimento. Não há um ambiente formalmente estruturado para a inovação e os estímulos são elogios, ascensão na função (embora não tenha plano de cargos e salários formalizados) e, esporadicamente, prêmios em dinheiro. A baixa rotatividade nessa empresa é contrária ao encontrado no mercado, esse fator é tido como algo que "faz a casa funcionar dentro da normalidade - palavras do entrevistado". O que enfatiza ainda mais que há uma memória organizacional que precisa ser preservada.

\section{CONSIDERAÇÕES FINAIS}

O objetivo foi identificar os elos de relação da gestão do conhecimento para a inovação em um restaurante de pequeno porte em uma cidade do Estado do Rio Grande do Norte. A pesquisa descritiva foi conduzida por um estudo de caso único de natureza qualitativa.

Assim identificou-se de forma conclusiva que os processos inovadores na empresa têm como único referencial dessas inovações os testemunhos dos sócios e colaboradores, as inovações já implantadas e outras em andamento e o grau de crescimento do porte da empresa, observados in loco, que passou de 06 colaboradores para mais de 50. Embora o restaurante seja sistematicamente inovador esse modelo informal de inovação é prática similar na maioria das empresas acompanhadas.

Basicamente a inovação acontece e está alicerçada em conhecimentos adquiridos, mas não geridos, não se aprende a aprender com ela, não se deixa registrado para gerações futuras. Segundo Barroso e Gomes (2013) essa prática tendo em vista a transitoriedade das pessoas diz que a mobilidade da mão-de-obra é um fato da vida moderna e a erosão da base do conhecimento da empresa ocorre a cada reposição. Para que esse fenômeno não ocorra é preciso fazer uso de mecanismos formais, e assim, o conhecimento individual possa ser transferível e se transformar em ativo intangível da empresa.

A limitação desse estudo se deu pelo fato de ser um estudo de caso único e não ter sido gerado as comparações que um múltiplo poderia proporcionar. Sendo assim, a sugestão para trabalhos futuros é a de acompanhar os processos inovadores nessa empresa e outras do mesmo segmento para uma análise mais aprofundada do tema.

\section{REFERÊNCIAS}

1. BACHMANN, D. L.; DESTEFANI, J. H. Metodologia para estimar o grau de inovação nas MPE. Curitiba, 2008. Disponível em: <http://www.bachmann.com.br/website/documents/Artigo GraudelnovacaonasMPE.pd> Acesso em: 30 jun. 2015.

2. BARDIN, Laurence. Análise de conteúdo. Lisboa: Edições 70, 1979.

3. BARNEY, Jay. Firm Resources and Sustained Competitive Advantage. Journal of Management, v. 17, n. 1, 99-120, 1991. 
4. BARROSO, Antonio Carlos de Oliveira; GOMES, Elisabeth Braz Pereira. Tentando entender a gestão do conhecimento. Revista de Administração Pública, v. 33, n. 2, p. 147-170, 2013.

5. BITENCOURT, Claudia; OLIVEIRA, Talita. Path dependence and path creation in volunteer partners, a non-governmental organization. Administração Contemporânea, v. 18, n. 3, jun. 2014

6. DAVENPORT, Thomas H. Conhecimento empresarial. São Paulo: Campus, 1998.

7. DINIZ, P. A. Metodologia científica. Belo Horizonte: FEAD, 2006.

8. FLICK, Uwe. Pesquisa qualitativa. Porto Alegre: Bookman, 2009.

9. FNQ. Modelo de Excelência de Gestão. Disponível. em: <http://www.fnq.org.br/avaliese/metodologia-meg/modelo-de-excelencia-da-gestao>. Acessado em out. 2014.

10. GIL, Antônio Carlos. Métodos e técnicas de pesquisa social. 5 ed. São Paulo: Atlas, 1999.

11. HESSEN, Johannes. Teoria do Conhecimento. São Paulo: Martins Fontes, 2000.

12. IBGE. Principais Estatísticas do Mercado Doméstico: Setor de Serviços. Disponível em: http://www.desenvolvimento.gov.br/sitio/interna/interna.php?area=4\&menu=4460. Acessado em out 2014.

13. INNOSCIENCE. Pesquisa Evolução da Gestão da Inovação nas Empresas Brasileiras. Disponível em: http://www.innoscience.com.br/?pg=PublicacoesPesquisas. Acessado em out 2014.

14. ISSUU. Anuário Brasileiro da Alimentação Fora do Lar 2013. Disponível em: http://issuu.com/aforadolar/docs/anu_rio_da_alimenta___o_fora_do_l. Acessado em 29 out 2014.

15. JOHANNESSEN, Jon-Arild; OLSEN Bjorn; OLAISEN, Johan. Aspects of innovation theory based on knowledge-management. International Journal of Information Management, n.19, p.124, 1999.

16. LAKATOS, Eva Maria, MARCONI, Mariana Andrade. Fundamentos de metodologia científica. 5 ed. São Paulo: Atlas 2003.

17. LASTRES, Helena M. M. Sarita Albagli. Informação e globalização na era do conhecimento. Rio de Janeiro: Campus, 1999.

18. MORGAN, Gareth. Imagens da Organização. São Paulo: Atlas 1996.

19. OLIVEIRA, Paulo Henrique de. et al. Um estudo sobre gestão do conhecimento e inovação em uma empresa multinacional do setor de fast-food: o caso da Subway. Perspectivas em Ciência da Informação, v.18, n.1, p. 86-105, jan/mar. 2013.

20. ORGANIZAÇÃO PARA COOPERAÇÃO ECONÔMICA E DESENVOLVIMENTO (OCDE). Manual de Oslo: diretrizes para coleta e interpretação de dados sobre inovação. 3. ed. Brasília: FINEP, 2006.

21. PEREZ, Gilberto et al. Adoção de inovações tecnológicas na área de saúde: um estudo sobre sistemas de informação sob a ótica da teoria de difusão. Journal of Information Systems and Technology Management, v. 7, n. 1, p. 71-94, 2010.

22. ROSSETTI, A. G. et al. A organização baseada no conhecimento: novas estruturas, estratégias e redes de relacionamento. Ciência da Informação, v. 37, n. 1, p. 61-72, 2008. 
23. SCHUMPETER, Joseph Alois. Teoria do desenvolvimento econômico. Fundo de Cultura, 1961.

24. SEBRAE. Inovação aberta: Conceitos e casos. Disponível em http://www.uc.sebrae.com.br/vi deo/inovacao-aberta-conceitos-e-casos. Acessado em out 2014.

25. SENGE, Peter. The fifth discipline. New York, Doubleday, 1990.

26. SEBRAE. Programa ALI ajuda a implantar práticas inovadoras gratuitamente no seu negócio. Disponível em: http://www.sebrae.com.br/sites/PortalSebrae/Programas/Agentes-Locais-deInova\%C3\%A7\%C3\%A3o:-receba-o-Sebrae-na-sua-empresa. Acessado em out 2014.

27. SEBRAE. Guia para a inovação: Instrumento de orientação de ações para melhoria das dimensões da Inovação. Disponível em <http://app.pr.sebrae.com.br/ali/>. Acessado em out 2014.

28. YIN, Robert K. Estudo de caso: planejamento e métodos. Trad. Daniel Grassi. - 3. ed. -Porto Alegre: Bookman, 2005. 